any student. It ends with a well-chosen summary which brings the organic chemistry of fluorine into its proper perspective. D. H. R. Barton, who has summarized the chemistry of the triterpenoids in thirty-six pages, usefully charts interrelationships of compounds of the $\alpha$-and $\beta$-amyrin, lupeol and lanosterol series and then confines his attention to topics of major structural significance. The chapter is admirable for reference but difficult to read and appreciate immediately.

In contrast, F. S. Spring's following chapter on the partial synthesis of cortisone is a precise but adequate essay on a much more restricted topic. It brings welcome clarity to a subject that is almost unreadably technical in the original literature, and makes sufficient use of clear structural formulæ to reveal to the reader at a glance both the mechanism and the stereochemistry of every reaction that it discusses. H. H. Inhoffen's chapter on relationships between natural steroids and carcinogenic compounds is again an adequate essay which collects facts new and old so as to give most readers a stimulating perspective of the wider significance of research in pure organic chemistry.

Finally, J. P. Wibaut, in reviewing pyridine chemistry in but forty pages, has again been forced to select topics from an immense subject. As would be expected from such an experienced teacher and writer, he has chosen his material in the interest of students. After exemplifying recent investigations of the structure and reactions of pyridine compounds, he finally devotes a few pages to pyridine alkaloids, pyridoxine and codecarboxylase. The whole chapter is excellent but far too short.

No organic chemist can put down this book without being conscious of the excellence of the printing. Clear, exact graphical formulæ are the prime requisite in any volume which deals with the complexities of modern researches in organic chemistry. Here they are presented with meticulous neatness and accompanied by typescript of adequate size. For this both the editor and the publisher deserve the highest praise.

W. A. Waters

\section{THE WORLD'S TRANSIENT ENERGY RESOURCES}

\section{Energy in the Future}

By Palmer Cosslett Putnam. Pp. $x+556+17$ plates. (Now York : D. Van Nostrand Company, Inc.; London: Macmillan and Co., Ltd., 1953.) 90s. nөt.

A $\mathrm{S}$ implied in its title, this book is a study of an A increasingly vital problem looming larger before the eyes of the world with every passing year. Mr. P. C. Putnam is an eminent engineer who has, for many years, been at the heart of research and development in the field of energy, in which he has had a distinguished career both in peace and in war. His book is the outcome, or digest, of a report made by him to the Atomic Energy Commission, and the scope of the inquiry is prodigious yet logical enough.

It begins with an attempt to assess the future world population, a necessary premise, since it is the population that uses up the energy. The first quarter of the book, therefore, concerns the value of predictions of the population of the world in A.D. 2050; and, deciding that it is unpredictable, it assumes a figure for which the author uses the word 'plausible', where others, perhaps, would prefer the term 'reasonable'. (The converse, 'implausible', will scarcely commend itself to our ears.)

A large number of tables and graphs contribute to the plausible figure arrived at, which presents the somewhat grim picture of 3,700 million in A.D. 2000 and no less than 6,300 million in A.D. 2050. Mr. Putnam has to omit possible factors, such as world disasters by plague and famine and world wars, since these are even more unpredictable than birthrates and longevity. The figure seems to be all too reasonable, though some will think that the author is too optimistic over the rate of advance he expects among the backward peoples. He seems to accept a rather rapid transition from what he calls the illiterate subsistence farming pattern of peoples to the literate industrial-urban-farm pattern.

The author, rightly despairing of any great accuracy in the figure, asks his reader to picture an imaginary prudent "Trustee of Energy" who will do his best to equate the growth of population with the energy available to give it a reasonable standard of living. The remaining three-quarters of the book is therefore devoted to a study of all the resources of energy, actual and potential, and the figures arrived at are just as grim as those for population. The study is very comprehensive and thorough, and accompanied by a wealth of tables and graphs. As was to be expected, the energy derived from capital resources of fuel is shown to be disappearing at an alarming rate. What the author graphically calls the "burn-up" of the fossil fuels (coal, oil and natural gas) is going on so fast that their end is measurable in a few score years at most in the main industrial countries. He has to relate the resources of these fuels still available to the cost of their recovery, and he accepts a reasonable ceiling for these costs at twice the 1950 costs.

Mr. Putnam then passes to "income" energy, including such diverse sources as wood-fuel, waterpower, wind-power and the energy potentially available from photosynthesis. As a first-rate engineer, he endeavours to reduce all these to plausible figures. From solar heat-collectors, for example, he manages to collect quite a respectable amount of energy, though he applies it mostly to what he calls "comfort energy", house heating, etc. Taken as a whole, however, the total of income energy is disappointing, and our benevolent and prudent Trustee can only find 12 per cent of the energy we need for the next century from that source, so he turns to the new field of nuclear fuels. The figures here are admittedly rather speculative, and, of course, nuclear energy is like coal - in the category of capital, a wasting asset. $\mathrm{He}$ reaches the conclusion that in A.D. 2050 the energy system of the world will comprise 15 per cent from income sources and 85 per cent from capital, of which nuclear fuels will have to provide 60 per cent.

Copious notes fill the latter half of the book, and in these (appendixes, as we should call them) there is a good deal of material which might well have deserved a place in the body of the book. This is particularly true of some thirty pages on the food situation of the future, and it is on this topic, curiously enough, that one meets a heartening conclusion: "Techniques within man's grasp could provide food, clothing and shelter for a world population many times the size of the present".

The book carries a warning to all and perhaps most clearly to the United States itself, that, in the words of the Trustee, it cannot continue to live at a high standard off its energy resources.

Frank Debenham 